\title{
Pattern of Poisoning Cases at Tertiary Care Center at Geetanjali Medical College \& Hospital, Udaipur
}

\author{
Lovekumar R. Bhagora ${ }^{1}$, Sanjeev Kumar ${ }^{2}$ \\ ${ }^{1}$ Assistant Professor, Dept. of Forensic Medicine, Geetanjali Medical College, Udaipur, ${ }^{2}$ Professor \& Head, \\ Dept. of Forensic Medicine, Geetanjali Medical College, Udaipur, Rajasthan
}

\begin{abstract}
Introduction: Poisoning is a global public health problem causing significant morbidity and mortality. It is important to know the pattern and outcome of acute poisoning cases for proper planning, prevention and management of these cases.

Aims and Objective: To find out the pattern of poisoning reported in Geetanjali Medical College, Udaipur.

Material and Methodology: The present prospective study had been conducted in the Department of Forensic Medicine, Geetanjali Medical College \& Hospital, Udaipur, Rajasthan during the period of Two year from $1^{\text {st }}$ Jan 2017 to $31^{\text {th }}$ Dec 2018.

Result and Observation: In our study majority of poisoning case [101 cases (35.69\%)] were observed in the age group of 21-30 years followed by the age group of 11-20 years. Male person [153 cases (54.06\%)] most commonly affected by poison and majority of patients [184 cases $(65.02 \%)]$ belongs to Rural area. In our study majority numbers of cases [128 cases (43.82\%)] found in rainy season. In our studyhigher number of poisoning cases were due to Aluminium phosphide poisoning [106 cases $(37.47 \%)$ ] followed by snakebite poisoning [62 cases (21.91\%)]. Among insecticides, maximum 40 cases $(14.13 \%)$ were due to Organophosphorus compounds. Conclusion:Awareness and education about the potential toxicity of commonly used pesticides and drugs may help in reducing the burden of poisoning
\end{abstract}

Keyword: Prospective study, Poison, Aluminium Phosphide, Snake bite, Organophosphorus, Udaipur.

\section{Introduction}

Poisoning is a global public health problem causing significant morbidity and mortality. It is important to know the pattern and outcome of acute poisoning cases for proper planning, prevention and management of these cases.

Mortality and morbidity of poisoning cases varies

\section{Corresponding Author:}

\section{Dr. Sanjeev Kumar}

Professor \& Head, Dept. of Forensic Medicine,

Geetanjali Medical College, Udaipur-313001,

Rajasthan

Contact No.: 9462700505

e-mail: drsanjeevkumar73@yahoo.com from country to country depending on the nature of poison and availability of facilities and treatment by qualified doctors ${ }^{1}$.

Poisoning is a medical emergency and a patient is always invariably rushed to the hospital at the earliest possible moment, irrespective of the amount and nature of poison ingested ${ }^{2}$.

Poisoning is one of the major causes of hospitalization through emergency and is a major public health problem ${ }^{3}$. Pattern of poisoning in a region depends on variety of factors, such as availability of the poisons, socio-economic status of the population, religious and cultural influences and availability of drugs.

Considering the cost and outcomes of the poison cases reported to the hospitals, it is found necessary 
to establish a Poison Information Centre (PIC) which should be networked with other poison information centres in India and with other countries, by which identifying the poisons and managing the cases will become more efficient ${ }^{4}$.

\section{Aims and Objective:}

To find out the pattern of poisoning reported to the hospital.

To determine the age and sex wise distribution of poisoning cases.

To find out the duration of hospital stay.

To find out nature and type of Poison

\section{Material and Methodology}

The present prospective study had been conducted in the Department of Forensic Medicine \& Toxicology at Geetanjali Medical College \& Hospital, Udaipur, Rajasthan during the period from $1^{\text {st }}$ Jan 2017 to $31^{\text {th }}$ Dec 2018.

The diagnosis of poisoning was based on history given by clinical examination, police officer, patient relatives and medical case papers.. Necessary laboratory tests were also performed to confirm the diagnosis of poisoning (if available). All cases of poisoning admitted to the hospital were included in this study. The data including demographic profile of patients, duration of hospital stay, nature and class of poison, outcome and circumstances of poisoning were obtained from medical records and were documented on a pre-structured proforma.

\section{Result and Observation}

In our study majority of case [101 cases (35.69\%)] were observed in the age group of 21-30 years followed by the age group of $11-20$ years [65 cases (22.26\%)] followed by $31-40$ years[46 cases $(16.25 \%)$ ]. While only 5 case $(01.77 \%)$ was observed in between $61-70$ years age group. [Table 1].

Majority [153 cases (54.06\%)] of cases of Poison were Male person while [130 cases (45.94\%)] were female. [Table 2]

In our study majority of cases[184 cases (65.02\%)] belongs to Rural area, while 99 cases (34.98\%) belongs to Urban area. [Table 3]
In our study majoritynumbers cases [128 cases (43.82\%)] of Poison found inrainy season [Table 4].

The hospitalization time for the poisoning cases in our study, varied between 1-37 days with a mean duration of hospitalization of 4 -7days. [Table 5].

In our studyOut of total 283 poison cases, Aluminium phosphide poisoning were found in 106 cases (37.47\%) followed by snakebite poisoning was there in 62 cases $(21.91 \%)$ and acid poisoning - 3 cases $(1.06 \%)$.Among insecticides, maximum - 40 cases $(14.13 \%)$ were due to the organophosphorus compounds. [Table 6].

\section{Discussion}

In the present study, majority of Poisoning cases $(21.30 \%)$ were observed in the age group of 21-30 years. which was also similar with various studies, like Gupta $\mathrm{P}$ et $\mathrm{al}^{5}$, Bari M S Vet $\mathrm{al}^{6}$. This shows that young adults are more vulnerable to this health problem which might be due to emotional and social disharmony, occupational problems and risk taking behaviors at these ages.

The pattern of poisoning with respect to gender in our study indicates that there were more cases of poisoning among the male patients $(54.06 \%)$ compared to female patients(45.94\%). This type of similar finding are observed by Gupta Pet $\mathrm{al}^{5}$, Bari M S V et $\mathrm{al}^{6}$. High proportion of poisoning among males might be due to change in the lifestyle and cultural patterns, reactive depression and high degree of stress in academic, financial and social sectors.

In the present study, majority of victims $(65.02 \%)$ were belongs to rural area, while $34.98 \%$ victims were belongs to urban area. Nearly similar finding are seen in the study done by Sharma BR et $\mathrm{al}^{7}$. This maybe because widespread use of pesticide in agriculture sector in rural area. Poverty, failure of crops, family problems and easy availability of the poison in their household made people of rural area more prone for poisoning. However, study done by Abubakar S etal ${ }^{8}$ from state of Karnataka, the incidence was more in those who were from urban background.

A season-wise variation was seen in the poisoning incidence in the present study. Maximum numbers of poisoning cases [128 cases $(43.82 \%)]$ were seen in the rainy season. This may be due to increased work and labour pressure, financial crisis and increased use and availability of pesticides, Insecticide during that season. Also snake bite cases more seen in this season. 
The hospitalization time for the poisoning cases in our study, varied between 1-37 days with $30.74 \%$ showing a mean duration of hospitalization of 4-7 days. A similar result was found in the study conductedby Abubakar S et $\mathrm{al}^{8}$ in southern India, which indicated that the average number of days of hospitalization was 4-7 days $(33.3 \%)$.

The Southern parts of Rajasthan, mostly comprising of agricultural land, the geographic distribution of the Victims chiefly being from rural areas and comprising of 184 cases. In our study most of cases of poisoning were due to Aluminium phosphide, Snake bite and Organophosphate poison.Because of abundant use of pesticides, Insecticides inagricultural fields of rural areas and inhabitation of poisonous reptiles (snakebite) in unhealthy and hillyrural areas.Organophosphate and aluminium phosphide are common agents used for poisoning because of low cost and easy availability and since majority of patients in our study were from rural background and were farmers, they used these pesticides instead of other poisons. Snake bite is also common in our study because of predominance of people of rural area.

Table 1: Age Wise Distribution of Poisoning Cases

\begin{tabular}{|c|c|c|}
\hline Age group & No. of Patient & Percentage (\%) \\
\hline $0-10$ & 25 & 8.83 \\
\hline $11-20$ & 63 & 22.26 \\
\hline $21-30$ & 101 & 35.69 \\
\hline $31-40$ & 46 & 16.25 \\
\hline $41-50$ & 21 & 7.42 \\
\hline $51-60$ & 22 & 7.77 \\
\hline $61-70$ & 5 & 1.77 \\
\hline $71-80$ & 0 & 0.00 \\
\hline Total & $\mathbf{2 8 3}$ & $\mathbf{1 0 0}$ \\
\hline
\end{tabular}

Table 2: Sex Wise Distribution of Poisoning Cases.

\begin{tabular}{|l|c|c|}
\hline Gender & No. of Patient & Percentage (\%) \\
\hline Male & 153 & 54.06 \\
\hline Female & 130 & 45.94 \\
\hline Total & 283 & 100 \\
\hline
\end{tabular}

Table 3: Locality Wise Distribution of Poisoning Cases

\begin{tabular}{|l|c|c|}
\hline Locality & No. of Patient & Percentage (\%) \\
\hline Urban & 99 & 34.98 \\
\hline Rural & 184 & 65.02 \\
\hline Total & $\mathbf{2 8 3}$ & $\mathbf{1 0 0}$ \\
\hline
\end{tabular}

Table 4: Season Wise Distribution of Poisoning Cases.

\begin{tabular}{|l|c|c|}
\hline Season & No. of Patient & Percentage (\%) \\
\hline Winter & 68 & 24.02 \\
\hline Summer & 91 & 32.16 \\
\hline Rainy & 124 & 43.82 \\
\hline Total & 283 & 100 \\
\hline
\end{tabular}

Table 5: Duration of Hospital Stay Wise Distribution of Poisoning Cases.

\begin{tabular}{|l|c|c|}
\hline $\begin{array}{l}\text { No. of days of } \\
\text { hospitalization }\end{array}$ & No. of Patient & Percentage (\%) \\
\hline Up to 1 day & 76 & 26.86 \\
\hline 1-3 day & 83 & 29.33 \\
\hline 4-7 day & 87 & 30.74 \\
\hline 8-15 day & 25 & 8.83 \\
\hline 16-30 day & 11 & 3.89 \\
\hline Above 30 day & 1 & 0.35 \\
\hline Total & $\mathbf{2 8 3}$ & $\mathbf{1 0 0}$ \\
\hline
\end{tabular}

Table 6: Type and Nature Poison Wise Distribution Of Poisoning Cases.

\begin{tabular}{|l|c|c|}
\hline Type of Poison & No. of Patient & $\begin{array}{c}\text { Percentage } \\
\text { (\%) }\end{array}$ \\
\hline Aluminium Phosphide & 106 & 37.46 \\
\hline Snake bite & 62 & 21.91 \\
\hline $\begin{array}{l}\text { Scorpion Venom \& Other } \\
\text { Arthropods }\end{array}$ & 24 & 8.48 \\
\hline Organo Phosphorus & 40 & 14.13 \\
\hline Insecticide Other than O.P. & 12 & 4.24 \\
\hline Corrosive Poison & 3 & 1.06 \\
\hline Miscellaneous Poison & 13 & 4.59 \\
\hline Psychotropic drug & 4 & 1.41 \\
\hline Alcohol & 4 & 1.41 \\
\hline Unknown & 15 & 5.30 \\
\hline Total & $\mathbf{2 8 3}$ & $\mathbf{1 0 0}$ \\
\hline
\end{tabular}




\section{Conclusion}

Most common type of poisoning cases reported overall was aluminium phosphide followed by snake bite followed by organophosphate. Proportion of mortality and requirement of ventilator was higher in case of aluminium phosphide poisoning. We suggest the government should regulate the import, manufacture, sale, transport, distribution and use of insecticides and pesticides. Upgrading the peripheral health centres to manage cases of poisoning in emergency including training of staff to give first aid treatment of poisoning (including timely intubation and respiratory support on AMBU bag) and availability of antidote and anti-snake venoms and increase in public awareness about the seriousness of problem through health education.

Awareness and education about the potential toxicity of commonly used pesticides and drugs may help in reducing the burden of poisoning. We should have to establish a poison information centre (PIC)which should be networked with other poison information centre in India and with developed countries which can help in identifying the poison and managing the cases.

Source of Funding: Self

\section{Conflict of Interest: Nil}

Acknowledgement: Nil

Ethical Clearance: It is taken from Ethical committee of Geetanjali Medical University, Udaipur.

\section{Reference}

1. Reddy KSN. The Essentials of Forensic Medicine and Toxicology. $34^{\text {th }}$ ed. Edition. 2017, P- 466.

2. Dash SK, Raju AS, Mohanty MK et al. Sociodemographic Profile of Poisoning Cases. JIAFM.2005; 27:133-8.

3. Marahatta SB, Singh J, Shrestha R, Koju R. Poisoning casesattending emergency department in Dhulikhel Hospital- KathmanduUniversity Teaching Hospital. Kathmandu University Medical Journal; 2009, Vol. 7(2) Issue 26, 152-6.

4. Kiran N, Shobharani RH, Jaiprakash V, Vanaja K. Pattern of poisoningreported at south Indian tertiary care hospital. Indian Journal ofForensic Medicine Toxicology. 2008;2(2).17-9.

5. Gupta P, Kumar A et al. Pattern of cases of acute poisoning in a rural Tertiary care center in northern india; National Journal of Community Medicine; Apr 2016; Volume 7(4); 307-310

6. Bari MS, Chakraborty SR, Alam MMJ et al. FourYear Study on Acute Poisoning Cases Admitted to a Tertiary Hospital in Bangladesh: Emerging Trend of Poisoning in Commuters. Asia Pac J Med Toxicol 2014;3:152-6.

7. Sharma BR, Relhan N, Gupta Net al. Trends of fatal poisoning in northern India: a ten year autopsy analysis. Journal of pharmacology and toxicology 2007;2(4):350-358.

8. Abubakar S,Githa K et al. A Study on Pattern of Poisoning Cases in a Tertiary Care Hospital, Bangalore; Indian Journal of Pharmacy Practice, Jan - Mar, 2014; Volume 7(1). 